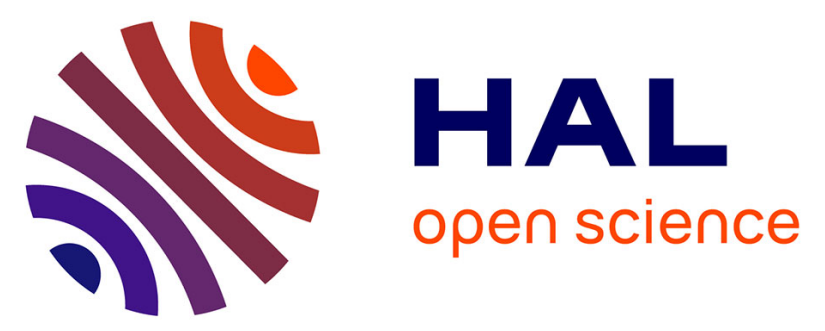

\title{
Fault Tolerant Control for Speed Sensor Failure in Induction Motor Drive based on Direct Torque Control and Adaptive Stator Flux Observer
}

Younes Azzoug, Arezki Menacer, Remus Pusca, Raphael Romary, Tarek Ameid, Abdelkarim Ammar

\section{To cite this version:}

Younes Azzoug, Arezki Menacer, Remus Pusca, Raphael Romary, Tarek Ameid, et al.. Fault Tolerant Control for Speed Sensor Failure in Induction Motor Drive based on Direct Torque Control and Adaptive Stator Flux Observer. 2018 International Conference on Applied and Theoretical Electricity (ICATE), Oct 2018, Craiova, Romania. pp.1-6, 10.1109/ICATE.2018.8551478 . hal-03276641

\section{HAL Id: hal-03276641 \\ https://hal-univ-artois.archives-ouvertes.fr/hal-03276641}

Submitted on 2 Jul 2021

HAL is a multi-disciplinary open access archive for the deposit and dissemination of scientific research documents, whether they are published or not. The documents may come from teaching and research institutions in France or abroad, or from public or private research centers.
L'archive ouverte pluridisciplinaire HAL, est destinée au dépôt et à la diffusion de documents scientifiques de niveau recherche, publiés ou non, émanant des établissements d'enseignement et de recherche français ou étrangers, des laboratoires publics ou privés. 


\section{Fault Tolerant Control for Speed Sensor Failure in Induction Motor Drive based on Direct Torque Control and Adaptive Stator Flux Observer}

\author{
Younes Azzoug ${ }^{1,2}$ \\ ${ }^{1}$ Electrical Engineering Department \\ Electrical Engineering Laboratory of \\ Biskra (LGEB) \\ Biskra, Algeria \\ younes.azzoug@univ-biskra.dz \\ Raphaël Romary ${ }^{2}$ \\ ${ }^{2}$ Univ. Artois, EA 4025 LSEE F-62400 \\ Bethune, France \\ raphael.romary@univ-artois.fr
}

\author{
Arezki Menacer ${ }^{1}$ \\ ${ }^{1}$ Electrical Engineering Department \\ Electrical Engineering Laboratory of \\ Biskra (LGEB) \\ Biskra, Algeria \\ menacer_arezki@hotmail.com \\ Tarek Ameid ${ }^{1}$ \\ ${ }^{1}$ Electrical Engineering Department \\ Electrical Engineering Laboratory of \\ Biskra (LGEB) \\ Biskra, Algeria \\ tarek-gnr@hotmail.fr
}

\author{
Rémus Pusca ${ }^{2}$ \\ ${ }^{2}$ Univ. Artois, EA 4025 LSEE F-62400 \\ Bethune, France \\ remus.pusca@univ-artois.fr
}

\author{
Abdelkarim Ammar ${ }^{3}$ \\ ${ }^{3}$ Institute of Electrical and Electronics \\ Engineering, Signal and Systems \\ Laboratory \\ Boumerdes, Algeria \\ abdelkarim.ammar@univ-boumerdes.dz
}

\begin{abstract}
This paper deals with a speed sensor fault tolerant control (FTC) scheme for induction motor (IM) drive based on direct torque control (DTC) and adaptive stator flux observer (ASFO). Many important points are treated in the proposed algorithm, which are the detection of the sensor failure, isolation of the faulty sensor and the reconfiguration of the control system by proper estimation. An adaptive stator flux observer is used instead of classical flux and torque estimator to perform the stator flux components, electromagnetic torque, flux magnitude, rotor position and the estimated rotor speed. Furthermore, a fault detection and isolation (FDI) logic circuitry is used to detect speed sensor fault and isolate it and simultaneously generate a logic impulse to switch to the sensorless mode. The proposed algorithm is simulated in MATLAB/Simulink.
\end{abstract}

Keywords-fault tolerant control, fault detection and isolation, direct torque control, induction motor, sensorless control, variable speed drives.

\section{INTRODUCTION}

Induction Motors (IMs) are broadly used in different applications for variable speed, simplicity of construction, less maintenance requirement, ruggedness, high performances and remarkable reliability are advantages that convince manufacturers to use this type of engines [1] [2]. To get high performances in variable speed control applications, many strategies of control are used, among them Sliding Mode Control, Backstepping Control, Field Oriented Control (FOC) and Direct Torque Control (DTC). The FOC method allows the decoupling between the flux and the torque to get an independent control like direct current machine [3]. On the other hand, FOC strategy needs transformations of current and voltage vectors [4] which is not the case in the DTC of IM drive, so the estimated flux and electromagnetic torque are directly used to generate the control pulses for voltage source inverter through a welldefined switching table [5].

The closed loop control like DTC which is presented in Fig. 1 needs feedback from speed and voltage sensors and two current sensors at least. Here, reliable operation of all control constituents gives satisfactory performances of all the drive system, but failure of any one of these components can cause the failure of the drive system. The failures in the drive systems are broadly classified as converter faults (semiconductors failure, power supply faults...), sensor faults (connection problems, noise, offset, the voltage drop of the battery...) and machine faults which are divided on two types, mechanical faults (eccentric rotor, bearing failures, shaft misalignment...) and electrical faults (broken bars, shorted circuit windings, insulation deterioration...).

In the last few years, there has been a growing interest on the Fault Tolerant Control (FTC) which is indispensable especially in the high-tech sectors such as air and railway transportation, astronomy, nuclear, medical industry... FTC techniques are designed for the purpose of detecting failures in the control chain and keeping a minimum dynamics of the control system after the occurring of the faults.

However, sensors are the most components susceptible to defects [6]. This work offers a Fault Detection and Isolation and fault tolerant control to speed/position sensor problems which is a basic component in adjustable speed drives, he gives informations that can be used to perform speed, position or torque control.

Several publications have been published in recent years documenting the speed sensor FTC, one of the examples of speed sensor FDI is presented in [7], the authors in this work propose a speed and current sensor FDI, whereas, the currents are estimated using d- and q- axis currents and the speed is estimated by using model reference adaptive system (MRAS), through a mechanism based on logic decisions to select the appropriate value and reconstruct the drive system. A FTC which depend on voting algorithms (VAs) is discussed in [8] [9] [10] while, the VAs choose the most correct output signal given by virtual sensors like sliding mode observer (SMO), adaptive Luenberger observer (ALO) and extended Kalman filter (EKF) to ensure the best behavior in the faulty mode. After all, a paper which resume presented approaches have been presented by [11], giving a bibliographical review about speed/position FDI and FTC in variable speed drives.

Therefore, this paper focuses on speed sensor direct torque fault tolerant control technique in induction motor drive systems. In the proposed algorithm, the detection of the 
speed sensor fault is accomplished by a logic circuitry which can detect the fault in the speed loop. Once, the sensor fault is identified, process of speed estimation becomes active. In this regard, an adaptive flux observer based on machine model is used to estimate the rotor speed moreover stator fluxes and electromagnetic torque. The logic circuitry performs the task of fault reconfiguration and isolation of the speed sensor at the faulty state. The proposed speed sensor FTC system can be globally used in any speed control strategies of IM. The proposed scheme is simulated and tested in MATLAB/Simulink under different operating conditions.

This paper is organized into VI sections; section II describes briefly the induction motor model and the direct torque control. Section III analysis the design of the adaptive stator flux observer. The adopted fault tolerant control method is presented in section IV. Afterwards, section V discusses the simulation results. Finally, section VI concludes the paper.

\section{INDUCTION MOTOR AND DIRECT TORQUE CONTROL}

The IM is explaned by the system equation below:

$$
\left\{\begin{array}{l}
\frac{d i_{\alpha s}}{d t}=-\left(\frac{R_{s}}{\sigma L_{s}}+\frac{R_{r}}{\sigma L_{r}}\right) i_{\alpha s}-\omega_{r} i_{\beta s}+\frac{R_{s}}{\sigma L_{s} L_{r}} \psi_{\alpha s}+\frac{\omega_{r}}{\sigma L_{r}} \psi_{\beta s}+\frac{1}{\sigma L_{s}} V_{\alpha s} \\
\frac{d i_{\beta s}}{d t}=-\left(\frac{R_{s}}{\sigma L_{s}}+\frac{R_{r}}{\sigma L_{r}}\right) i_{\beta s}-\omega_{r} i_{\alpha s}+\frac{R_{s}}{\sigma L_{s} L_{r}} \psi_{\beta s}+\frac{\omega_{r}}{\sigma L_{r}} \psi_{\alpha s}+\frac{1}{\sigma L_{s}} V_{\beta s} \\
\frac{d \psi_{\alpha s}}{d t}=V_{\alpha s}-R_{s} i_{\alpha s} \\
\frac{d \psi_{\beta s}}{d t}=V_{\beta s}-R_{s} i_{\beta s}
\end{array}\right.
$$

Where:

$V_{\alpha s}, V_{\beta s}$ are the stator voltage components. $i_{\alpha s}, i_{\beta s}$ are the stator current components. $\psi_{\alpha s}, \psi_{\beta s}$ are the stator flux components. $R_{s}, R_{r}$ stator and rotor resistance. $L_{s}, L_{r}$ stator and rotor inductance. $\omega_{r}$ rotor angular speed.

$\sigma=1-\frac{M^{2}}{L_{s} L_{r}}$, where $M$ is mutual stator-rotor inductance.

The electromagnetic torque is expressed by the following equation:

$$
T_{e}=p\left(\psi_{\alpha s} i_{\beta s}-\psi_{\beta s} i_{\alpha s}\right)
$$

The DTC basic idea is to calculate flux and torque instaneous values only from the stator variables.

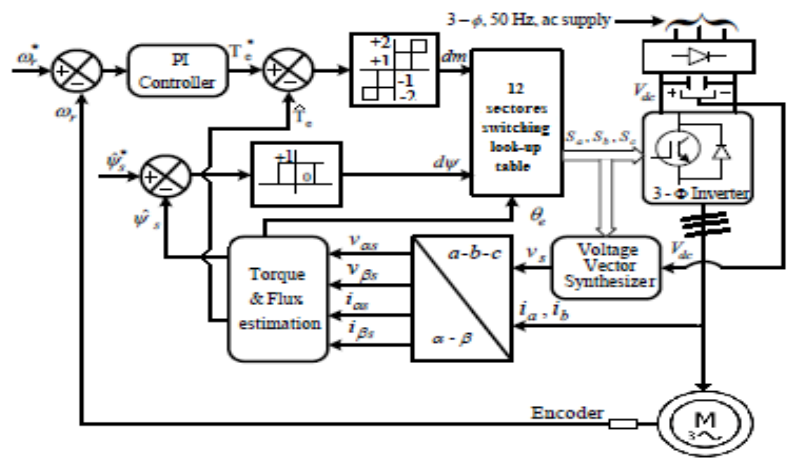

Fig. 1. DTC scheme of IM drive used in the presente paper.

\section{ADAPTIVE STATOR FLUX OBSERVER}

The IM model given in (1) is described by the following state equation [12]:

$$
\left\{\begin{array}{l}
\dot{X}=A(\omega) X+B U \\
Y=C X
\end{array}\right.
$$

Where

$$
X=\left[\begin{array}{llll}
I_{\alpha s} & I_{\beta s} & \psi_{\alpha s} & \psi_{\beta s}
\end{array}\right]^{T}, Y=\left[\begin{array}{ll}
I_{\alpha s} & I_{\beta s}
\end{array}\right]^{T}, U=\left[\begin{array}{ll}
V_{\alpha s} & V_{\beta s}
\end{array}\right]^{T}
$$

And

$A=\left[\begin{array}{cccc}a_{1} & 0 & a_{2} & \omega_{r} a_{3} \\ 0 & a_{1} & -\omega_{r} a_{3} & a_{2} \\ a_{4} & 0 & a_{5} & -\omega_{r} \\ 0 & a_{4} & \omega_{r} & a_{5}\end{array}\right], B=\left[\begin{array}{cc}\frac{1}{\sigma L_{s}} & 0 \\ 0 & \frac{1}{\sigma L_{s}} \\ 0 & 0 \\ 0 & 0\end{array}\right]$,

$C=\left[\begin{array}{llll}1 & 0 & 0 & 0 \\ 0 & 1 & 0 & 0\end{array}\right]$

Which

$a_{1}=-\left(\frac{1}{T_{s} \sigma}+\frac{(1-\sigma)}{T_{r} \sigma}\right), a_{2}=\frac{M}{\sigma L_{s} L_{r} T_{r}}, a_{3}=\frac{M}{\sigma L_{s} L_{r}}$,

$a_{4}=\frac{M}{T_{r}}, a_{5}=-\frac{1}{T_{r}}, T_{s}=\frac{L_{s}}{R_{s}}, T_{r}=\frac{L_{r}}{R_{r}}$

The adaptive stator flux observer scheme is presented in Fig. 2 with parameters considered in (4). ASFO equation is given by [13]:

$$
\left\{\begin{array}{l}
\hat{\dot{X}}=A\left(\hat{\omega}_{r}\right) \hat{X}+B U+K \xi_{y} \\
\hat{Y}=C \hat{X}
\end{array}\right.
$$

The symbol $\wedge$ denote estimated value and $K$ is the observer gain matrix, using the Lyapunov theory to deduce the mechanism of adaptation speed [14]. The stator current and stator flux estimation error is given by [15]:

$$
\dot{e}=(A-K C) e+(\Delta A) \hat{X}
$$


with

$$
\Delta A=A\left(\omega_{r}\right)-A\left(\hat{\omega}_{r}\right)=\left[\begin{array}{cccc}
0 & 0 & 0 & a_{3} \Delta \omega_{r} \\
0 & 0 & -a_{3} \Delta \omega_{r} & 0 \\
0 & 0 & 0 & -\Delta \omega_{r} \\
0 & 0 & \Delta \omega_{r} & 0
\end{array}\right]
$$

and

$$
\begin{gathered}
\Delta \omega_{r}=\omega_{r}-\hat{\omega}_{r} \\
e=X-\hat{X}=\left[\begin{array}{llll}
e_{I_{\alpha s}} & e_{I_{\beta s}} & e_{\psi_{\alpha s}} & e_{\psi_{\beta s}}
\end{array}\right]^{T}
\end{gathered}
$$

Considering the following Lyaponov function:

$$
V=e^{T} e+\left(\Delta \omega_{r}\right)^{2} / \lambda
$$

Where, $\lambda$ is a positive constant.

The derivative of (9) is as follows:

$$
\begin{gathered}
\frac{d V}{d t}=\left\{\frac{d\left(e^{T}\right)}{d t}\right\} e+e^{T}\left\{\frac{d e}{d t}\right\}+\frac{1}{\lambda} \frac{d}{d t}\left(\Delta \omega_{r}\right)^{2} \\
\frac{d V}{d t}=e^{T}\left\{(A-K C)^{T}+(A-K C)\right\} e-2 a_{3} \Delta \omega_{r}\left(e_{I_{\alpha s}} \hat{\psi}_{\beta s}-e_{I_{s s}} \hat{\psi}_{\alpha s}\right) \\
+\frac{2}{\lambda} \Delta \omega_{r} \frac{d}{d t} \hat{\omega}_{r}
\end{gathered}
$$

With $\hat{\omega}_{r}$ is the rotor velocity estimated by the adaptive observer. The rotor speed estimation is given by the Eq. 12, obtained through equality between the second and the third term of Eq. 11:

$$
\hat{\omega}_{r}=\lambda a_{3} \int_{0}^{t}\left(e_{I_{\alpha s}} \hat{\psi}_{\beta s}-e_{I_{\beta s}} \hat{\psi}_{\alpha s}\right) d t
$$

The expression (12) is established for a constant velocity, so as to ameliorate the feedback of the rotor position estimation in various condition, the law of the control is modified according to the following relation:

$$
\hat{\omega}_{r}=K_{p}\left(e_{I_{\alpha s}} \hat{\psi}_{\beta s}-e_{I_{\beta s}} \hat{\psi}_{\alpha s}\right)+K_{i} \int\left(e_{I_{\alpha s}} \hat{\psi}_{\beta s}-e_{I_{\beta s}} \hat{\psi}_{\alpha s}\right) d t
$$

With $K_{p}$ and $K_{i}$ are the positive gains of the PI controller. The return loop of the gain matrix $K$ is selected to ensure the high dynamics and performances of the global ASFO.

$$
K=\left[\begin{array}{cccc}
K_{1} & K_{2} & K_{3} & K_{4} \\
-K_{2} & K_{1} & -K_{4} & K_{3}
\end{array}\right]^{T}
$$

with $K_{1}, K_{2}, K_{3}$ and $K_{4}$ are given by:

$$
\left\{\begin{array}{l}
K_{1}=(l-1)\left(\frac{1}{\sigma T_{s}}+\frac{1}{\sigma T_{r}}\right) \\
K_{2}=-(l-1) \hat{\omega}_{r} \\
K_{3}=\left(l^{2}-1\right)\left\{\left[\frac{1}{\sigma T_{s}}+\frac{1}{\sigma T_{r}}\right] \frac{\sigma L_{s} M}{L_{r}}-\frac{M}{T_{r}}\right\}+\frac{\sigma L_{s} M}{L_{r}}\left[\frac{1}{\sigma T_{s}}+\frac{1}{\sigma T_{r}}\right](l-1) \\
K_{4}=-(l-1) \frac{\sigma L_{s} M}{L_{r}} \hat{\omega}_{r}
\end{array}\right.
$$

where $l$ is a positive constant.

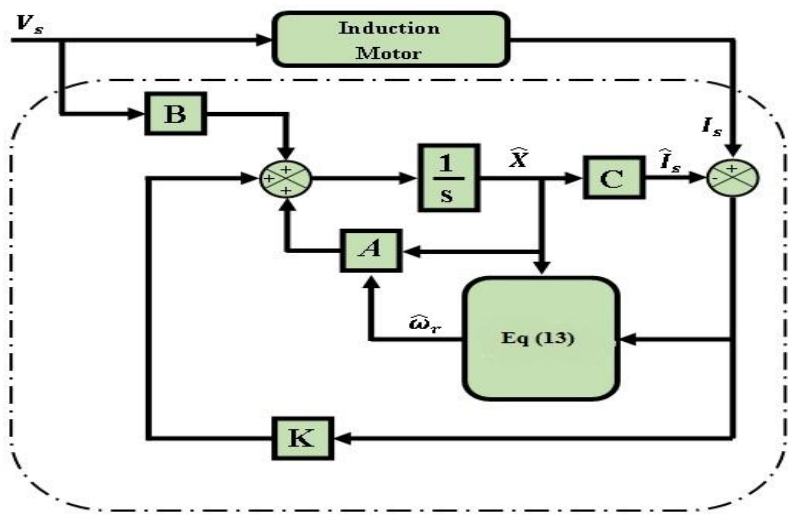

Fig. 2. Overall diagram of the adaptive observer

\section{SPEED SENSOR FAULT TOLERANT CONTROL}

By using the adaptive stator flux observer instead of the torque and flux estimator in the direct torque control scheme (Fig. 5), we can get the electromagnetic torque and stator flux components, in addition, estimated rotor speed. To detect speed sensor failures and isolate them, a thresholdbased scheme (Fig. 3) is proposed to allow to the motor drive system to switch to speed sensorless control mode in the case of speed sensor failure.

As it is seen from Fig. 3 and described in Table I, before the speed sensor failure, the IM drive system rest on DTC with speed sensor feedback, FDI generates a signal $Z=0$. In the case of failure in the speed sensor, FDI generates an impulse at the faulty instant $\mathrm{Z}=1$ to switch from measured speed to estimated speed. The FDI is based on calculation of the error (Er) between estimated and measured speed which will be pass through a low-pass filter (LPF) in order to extract the useful signal, this error is compared to a threshold (Th) well defined according to the reference speed.

TABLE I. IDENTIFICATION OF THE STATE OF THE SPEED SENSOR

\begin{tabular}{|l|c|c|}
\cline { 2 - 3 } \multicolumn{1}{c|}{} & \multicolumn{2}{c|}{ Speed sensor state } \\
\cline { 2 - 3 } \multicolumn{1}{c|}{} & Healthy state & Faulty state \\
\hline $\begin{array}{l}\text { Fault } \\
\text { indicator } \mathrm{Z}\end{array}$ & 0 & 1 \\
\hline
\end{tabular}

However, after several tests on the studied system, the threshold (Th) is defined as follows:

$$
T h=\left\{\begin{array}{l}
0.045\left|\omega_{r}^{*}\right| \quad \text { if } \quad\left|\omega_{r}^{*}\right|>200[r p m] \\
0.1\left|\omega_{r}^{*}\right| \text { if } \quad\left|\omega_{r}^{*}\right| \leq 200[r p m]
\end{array}\right.
$$

$\omega_{r}^{*}:$ reference speed 


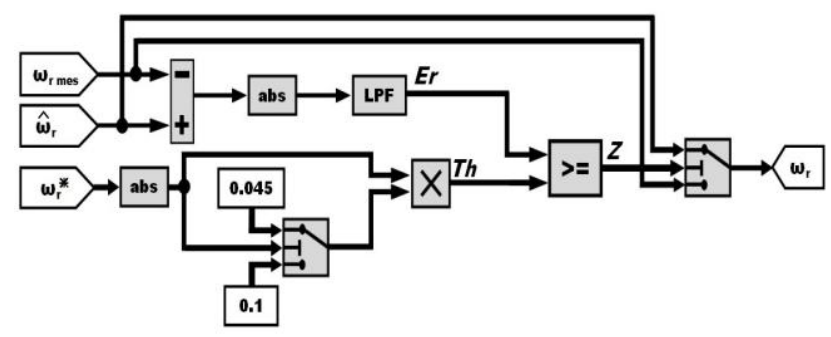

Fig. 3. Scheme of the fault detection and isolation system.

Fig. 4 shows the details flowchart for the proper selection of measured or estimated speed in the different states of the speed sensor, while, Fig. 5 illustrates the block diagram of DTC scheme for speed sensor FTC.

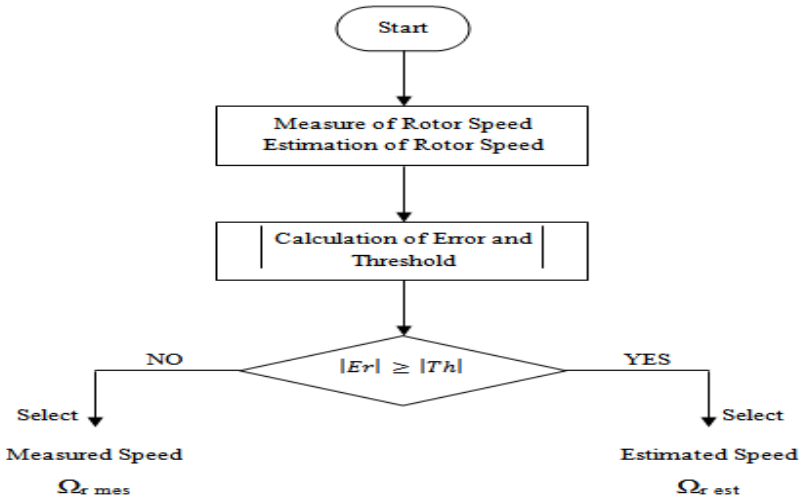

Fig. 4. Flowchart for the selection of measured and estimated speed.

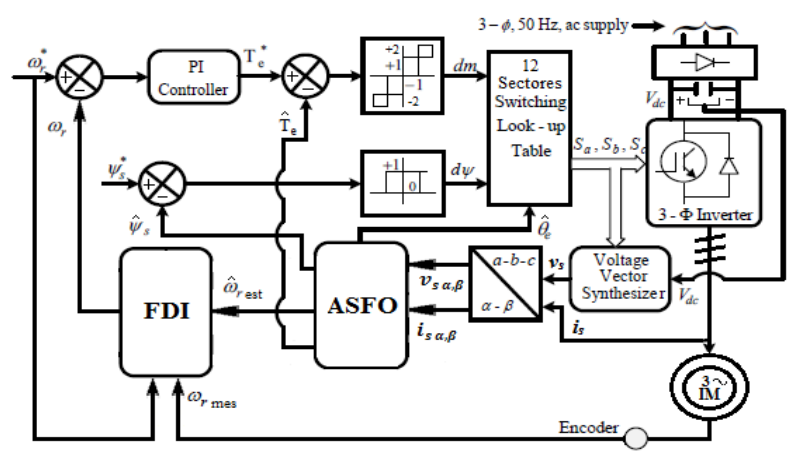

Fig. 5. Block diagram of DTC scheme for speed sensor fault tolerant control.

\section{Simulation RESUlts}

The behavior of the proposed fault tolerant control for speed sensor failures in induction motor drive based on direct torque control and adaptive stator flux observer is verified in simulation with MATLAB/Simulink at rated load (5 N.m) using nominal motor parameters presented in Appendix A.

Fig. 6 represents simulation results characterizing the performances of the FTC under the cited condition. At the healthy state, a step of $1000 \mathrm{rpm}$ in speed command is applied at $0 \mathrm{~s}$. Total failure of the speed sensor is simulated using a switch circuit in Simulink at 1s. Fig. 6(a) shows reference speed $\left(\omega_{r}^{*}\right)$, measured speed $\left(\omega_{r_{-} \text {mes }}\right)$, estimated speed ( $\hat{\omega}_{r}$ or $\omega_{r_{-} e s t}$ ) and the speed chosen by FDI algorithm $\left(\omega_{r}\right)$ according to system state, which depict an uninterrupted speed tracking by the estimated speed in the event of total speed sensor failure. The fault indicator $\mathrm{Z}$ explained in Table I is given in Fig. 6(b). From this figure it can be seen that, at the healthy state fault indicator $\mathrm{Z}$ is 0 but at $\mathrm{t}=1 \mathrm{~s}$, fault indicator $\mathrm{Z}$ is 1 which means that the speed sensor is in the faulty state. As can be seen from Fig. 6(c), the FDI algorithm makes the decision from calculating error (Er) between reference and measured speeds compared to the defined threshold (Th). Fig. 6(d) outlines continuous accomplishment of load torque requirement on this sensor failure. Stator currents, flux magnitude and flux components can be found in Fig. 6(e), Fig. 6(f) and Fig. 6(g) respectively. It can be seen that the technique in use gives a good performances even at faulty state, the flux magnitude flows its reference $\left(\psi_{r}^{*}=0.81 \mathrm{~Wb}\right)$, the stator flux $(\alpha, \beta)$ axis components and stator currents show perfect sinusoid waveform.
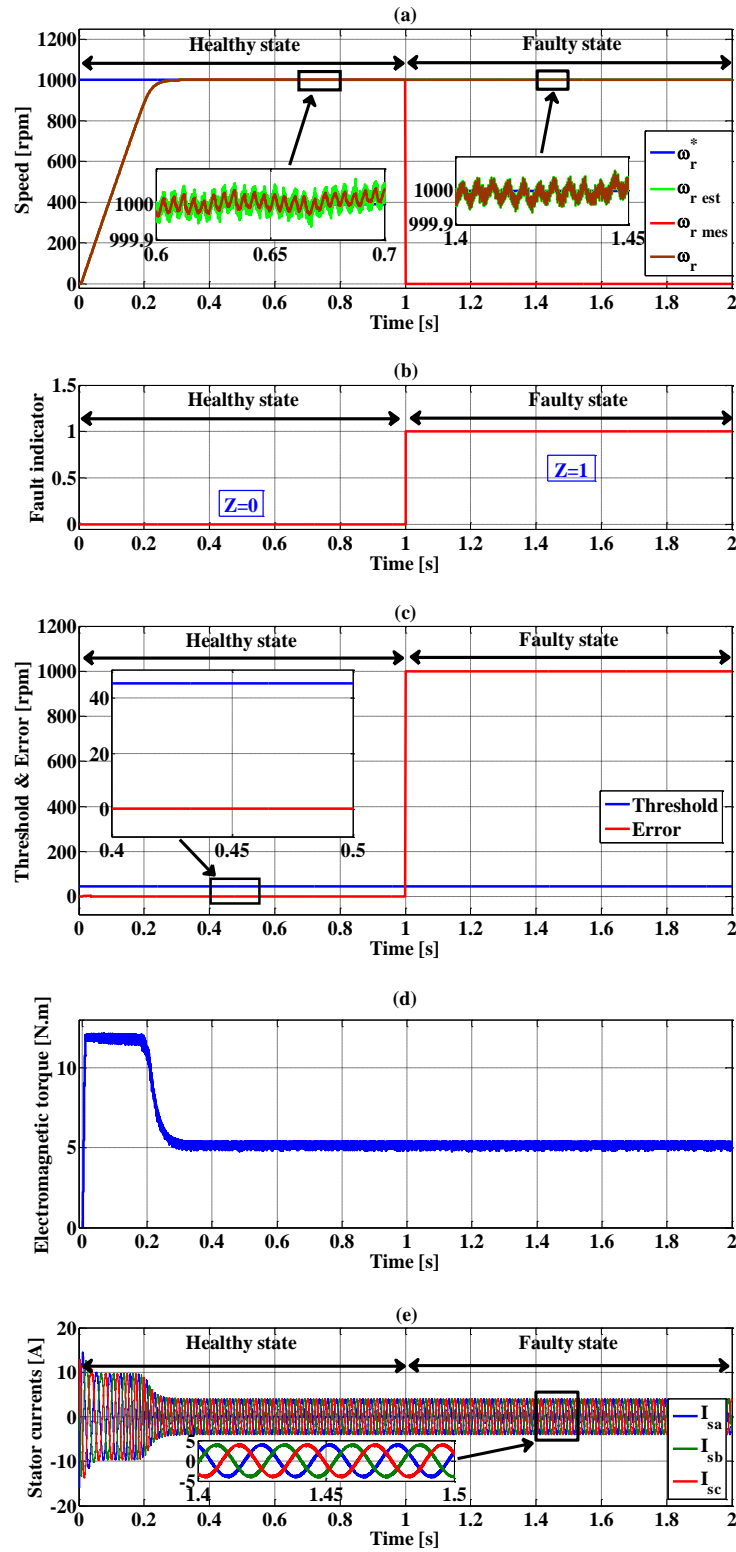

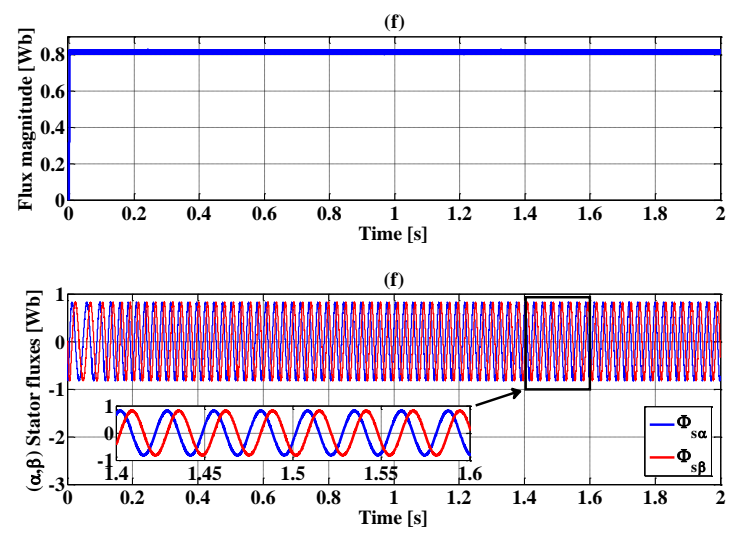

Fig. 6. Simulation results with total failure of the speed sensor at 1000 rpm and rated load (5 N.m): (a) reference, measured and estimated speed, (b) fault indicator, (c) threshold and error, (d) electromagnetic torque, (e) three-phase stator currents, (f) stator flux magnitude, (g) stator flux components.

Considering Fig. 7, this plots the behavior of the fault tolerant control system at low speed $(200 \mathrm{rpm})$ versus total failure of sensor speed. Initially the system was operating with a healthy speed sensor and at $\mathrm{t}=1 \mathrm{~s}$; the output of sensor speed becomes 0 as given by Fig. 7(a). Here we can see that the estimated speed ensure the continuity of drive system. Fault indicator $\mathrm{Z}$ can be found in Fig. 7(b), $\mathrm{Z}$ becomes 1 when sensor speed made to 0. Fig. 7(c) gives another example about the process of the FDI algorithm by calculating the error and the threshold which is in this case $10 \%$ of reference speed $(20 \mathrm{rpm})$ and compares them to give the decision to switch from sensor mode to the sensorless mode. Electromagnetic torque, stator currents, flux magnitude and flux components are shown in Fig. 7(d), 7(e), 7(f) and Fig. 7(g). We can see that the adaptive stator flux observer gives a satisfactory estimation of these quantities which are necessary to preserve the principle of the DTC.
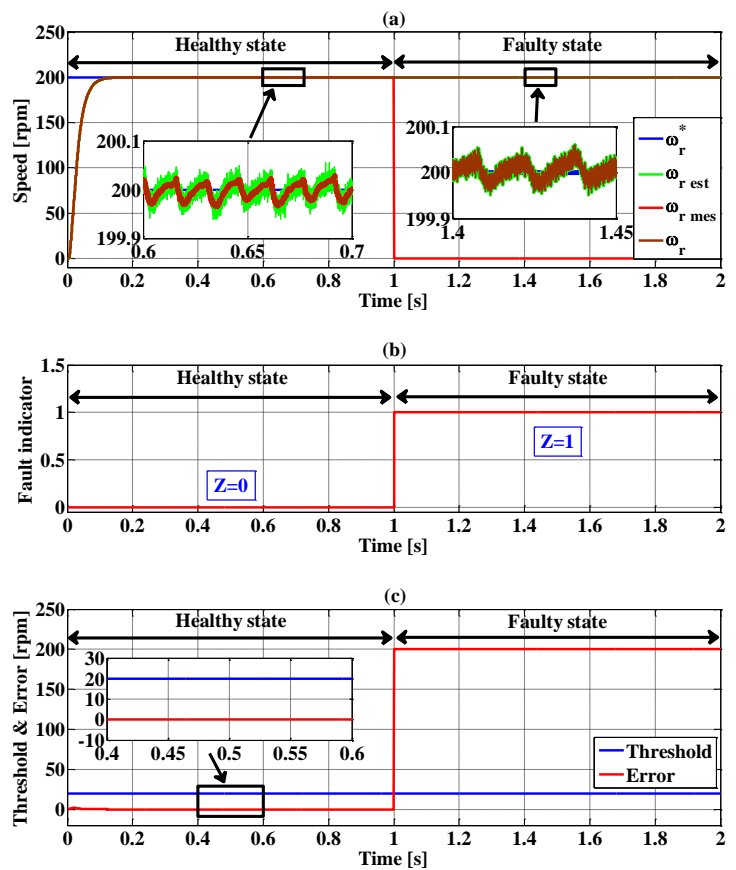
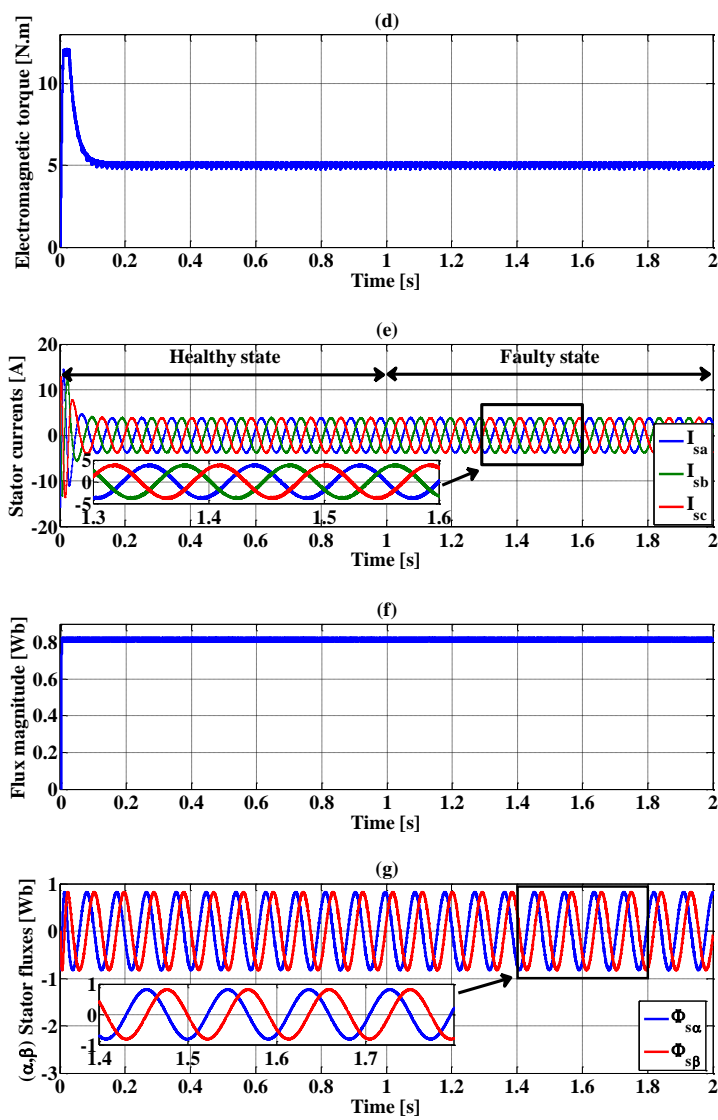

Fig. 7. Simulation results with total failure of the speed sensor at low speed (200 rpm) and rated load (5 N.m): (a) reference, measured and

estimated speed, (b) fault indicator, (c) threshold and error, (d) electromagnetic torque, (e) three-phase stator currents, (f) stator flux magnitude, $(\mathrm{g})$ stator flux components.

To investigate the high performances of the system, the fault tolerant control algorithm was tested in variable speed, Fig. 8 represent simulation results in case of Benchmark industrial test. The scenario of speed sensor fault is tested by switching off the speed sensor at $\mathrm{t}=1.1 \mathrm{~s}$ when the $\mathrm{IM}$ is running at $600 \mathrm{rpm}$, after failure, a step change in reference speed is applied. Results shown in Fig. 8(a) and 8(b) indicate a successful and high performance fault tolerant control system response.
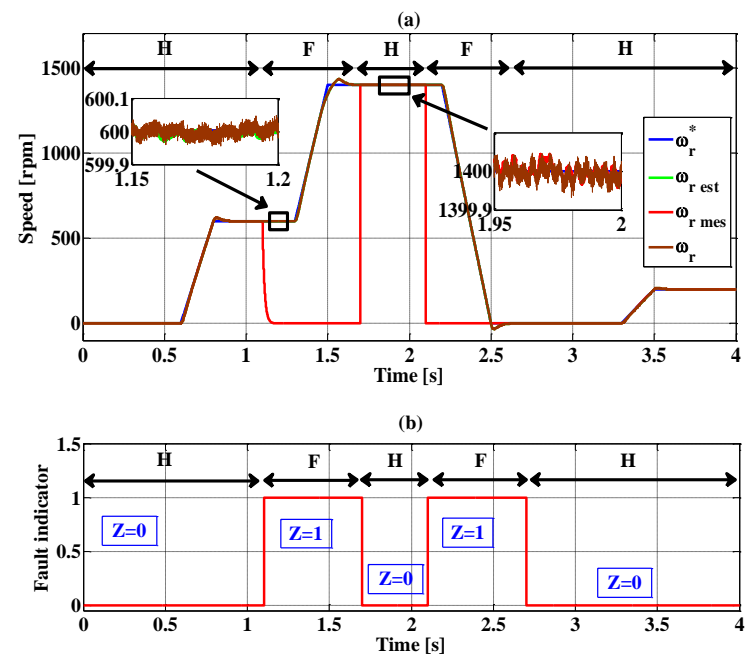

Fig. 8. Simulation results with total failure of the speed sensor following Benchmark trajectory: (a) reference, measured and estimated speed, (b) fault indicator. 


\section{CONCLUSION}

The main concern of the paper is the fault tolerant control for speed sensor failure in induction motor drive based on direct torque control and stator flux adaptive observer. For detecting the failures in speed sensor, a fault detection and isolation developed algorithm was employed. FDI system in the speed loop can detect any failure in the speed measurement by calculating error between reference and measured speed and compare this error to a well defined threshold. An adaptive stator flux observer is adopted to estimate rotor speed and stator flux components. In the moment of failure in speed sensor, a decision-making logic circuit automatically selects the sensorless mode to continue the drive uninterrupted system. The analytic model is presented in the paper and the simulation results ensure the satisfactory operation of the fault tolerant control proposed scheme.

APPENDIX A

\begin{tabular}{ll|ll}
\hline \multicolumn{1}{c|}{ Specifications } & \multicolumn{2}{c}{ Parameters } \\
\hline Nominal power [kW] & 1.1 & $\mathrm{R}_{\mathrm{s}}[\Omega]$ & 6.75 \\
Nominal voltage [V] & 400 & $\mathrm{R}_{\mathrm{r}}[\Omega]$ & 6.21 \\
Nominal current [A] & 2.5 & $\mathrm{~L}_{\mathrm{s}}[\mathrm{H}]$ & 0.5192 \\
Frequency [Hz] & 50 & $\mathrm{~L}_{\mathrm{r}}[\mathrm{H}]$ & 0.5192 \\
Number of pole pairs & 2 & $\mathrm{M}[\mathrm{H}]$ & 0.4957 \\
Nominal speed [rpm] & 1450 & $\mathrm{~J}\left[\mathrm{Kg} \cdot \mathrm{m}^{2}\right]$ & 0.0124 \\
& & $\mathrm{f}\left[\mathrm{Nm} \cdot \mathrm{sad}^{-1}\right]$ & 0.002 \\
\hline
\end{tabular}

\begin{tabular}{|c|c|c|c|c|}
\hline $\boldsymbol{K}_{p}$ & $\boldsymbol{K}_{\boldsymbol{i}}$ & Flux limit & Torque limit & $\boldsymbol{l}$ \\
\hline 1.4758 & 38.9969 & \pm 0.005 & \pm 0.0001 & 1.0005 \\
\hline
\end{tabular}

\section{REFERENCES}

[1] T. Ameid, A. Menacer, H. Talhaoui, and I. Harzelli, "Broken rotor bar fault diagnosis using fast Fourier transform applied to fieldoriented control induction machine: simulation and experimental study," Int. J. Adv. Manuf. Technol., vol. 92, no. 1-4, pp. 917-928, Sep. 2017.

[2] T. Ameid, A. Menacer, H. Talhaoui, and Y. Azzoug, "Discrete wavelet transform and energy eigen value for rotor bars fault detection in variable speed field-oriented control of induction motor drive," ISA Trans., May 2018.

[3] F. Blaschke, "The Principle of Field Orientation as Applied to the NEW Transvector Closed-Loop System for Rotating-Field Machines," Siemens Rev., vol. 34, no. 3, pp. 217-220, 1972.

[4] V. N. N, A. Panda, and S. P. Singh, "A Three-Level Fuzzy-2 DTC of Induction Motor Drive Using SVPWM," IEEE Trans. Ind. Electron., vol. 63, no. 3, pp. 1467-1479, Mar. 2016.
[5] M. Manohar and S. Das, "Current Sensor Fault-Tolerant Control for Direct Torque Control of Induction Motor Drive Using Flux-Linkage Observer," IEEE Trans. Ind. Informatics, vol. 13, no. 6, pp. 28242833, Dec. 2017.

[6] Y. Yu, Z. Wang, D. Xu, T. Zhou, and R. Xu, "Speed and Current Sensor Fault Detection and Isolation Based on Adaptive Observers for IM Drives," J. Power Electron., vol. 14, no. 5, pp. 1598-2092, 2014.

[7] C. Chakraborty and V. Verma, "Speed and Current Sensor Fault Detection and Isolation Technique for Induction Motor Drive Using Axes Transformation," IEEE Trans. Ind. Electron., vol. 62, no. 3, pp. 1943-1954, Mar. 2015.

[8] M. Boukhnifer, A. Raisemche, D. Diallo, and C. Larouci, "Fault tolerant control to mechanical sensor failures for Induction Motor drive: A comparative study of voting algorithms," in IECON 2013 39th Annual Conference of the IEEE Industrial Electronics Society, 2013, pp. 2851-2856.

[9] B. Tabbache, M. E. H. Benbouzid, A. Kheloui, and J.-M. Bourgeot, "Virtual-Sensor-Based Maximum-Likelihood Voting Approach for Fault-Tolerant Control of Electric Vehicle Powertrains," IEEE Trans. Veh. Technol., vol. 62, no. 3, pp. 1075-1083, Mar. 2013.

[10] A. Gouichiche, M. Zabar, Z. Chedjara, A. Safa, and M. Tadjine, "Expiremental validation of a fault tolerant control of induction motor using a voting algorithm," in 2015 3rd International Conference on Control, Engineering \& Information Technology (CEIT), 2015, vol. 0, no. 1, pp. 1-6.

[11] M. Bourogaoui, H. B. A. Sethom, and I. S. Belkhodja, "Speed/position sensor fault tolerant control in adjustable speed drives - A review," ISA Trans., vol. 64, pp. 269-284, Sep. 2016

[12] A. Ammar, A. Bourek, and A. Benakcha, "Nonlinear SVM-DTC for induction motor drive using input-output feedback linearization and high order sliding mode control," ISA Trans., vol. 67, pp. 428-442, Mar. 2017.

[13] H. Saberi, M. Feyzi, M. B. B. Sharifian, and M. Sabahi, "Improved sensorless direct torque control method using adaptive flux observer," IET Power Electron., vol. 7, no. 7, pp. 1675-1684, Jul. 2014.

[14] A. Ammar, A. Benakcha, and A. Bourek, "Adaptive MRAC-based direct torque control with SVM for sensorless induction motor using adaptive observer," Int. J. Adv. Manuf. Technol., Dec. 2016.

[15] C. Djamila, M. Yahia, and T. Ali, "Simultaneous Estimation of Rotor Speed and Stator Resistance in Sensorless Indirect Vector Control of Induction Motor Drives Using a Luenberger Observer," Int. J. Comput. Sci. Issues, vol. 9, no. 3, No 2, pp. 325-335, 2012. 